\title{
Optimization Design of Sucker Rod Centralizer Spacing in Straight Hole
}

\author{
Wen Sun ${ }^{\mathrm{a}}$, Bin Feng, Tao Ren, and Xiaoqing Kang \\ School of Mechanical Engineering, Xi'an Shiyou University, Shaanxi, Xi'an,710065, P.R.China \\ a sunwen@xsyu.edu.cn.
}

Keywords: Centralizer; Eccentric wear of rods and tubing; Optimization design

\begin{abstract}
The usage rate of sucker rod centralizer more and more broad with the development of a sucker rod pump, adding sucker rod centralizer is very effective to reduce the impact of rod and tubing wear, increase the sucker rod and tubing service life, reduce the frequency of maintenance and the production cost .Comprehensively considerated bending stress condition of sucker rod string during the down stroke, to establish axial load of a sucker rod mechanical model. Through the instability equation of sucker rod between two centralizers to optimize design of centralizer .The example analyzed shows that the optimum design of sucker rod centralizer spacing is feasible.
\end{abstract}

\section{Introduction}

The friction and wear between sucker rod and tubing is always an important issue needs resolution during the rod pumping system works steadily, It will cause sorts of downhole accidents indirectly, result in oil well stop production, increase oil well maintenance times and repair costs and directly affect the oil well production benefit [1-3].There are many ways to avoid rod tube eccentric wear, which adds centralizer on sucker rod is a general recognition in fields, it's not only has good effect but low cost. Sucker rod centralizer is very effective to reduce the impact of rod and tubing wear, increase the sucker rod and tubing service life and reduce the frequency of maintenance and the production cost.

At present ,the optimum locating positions and intervals of the rod centralizers lacking of support theory to guide and carry out concrete basis, most wells are configured by experience to design the locating positions and intervals of the rod centralizers, in addition to observing wear during the work -over, to position centralizer at badly worn, It not only can effectively prevent the rod tube eccentric wear but increase the cost maintenance. This paper comprehensively considerated bending stress condition of sucker rod string during the down stroke and established axial load of a sucker rod mecha -nical model, through the instability equation of sucker rod between two centralizers to optimize design of centralizer.

\section{Axial load of a sucker rod during the down stroke}

Axial force at the bottom of a sucker rod. A sucker rod is limited at the bottom by a variety of load included the buoyancy of well liquid and the sucker-rod string, the friction force between the piston and the bush and the friction force of well fluid through the subsurface pump during the down stroke.

(a) The buoyancy of well liquid and the sucker-rod string $W_{f}$

$$
W_{f}=\rho_{L} g A_{r} L_{p}
$$

Where, $\rho_{L}$ is liquid density; $A_{r}$ is sucker-rod section area; $L_{p}$ is pump depth; $g$ is acceleration of gravity.

(b) The friction force between the piston and the bush $W_{b p}$

The friction force exists in up and down stroke, recommended the empirical formula is

$$
W_{b p}=0.94 \frac{D}{\delta}-140
$$


Where, $\mathrm{D}$ is pump diameter; $\delta$ is clearance between the piston and the bush.

(c) The friction force of well fluid through the subsurface pump $W_{p L}$

The friction force exists in down stroke which direction is upward, the friction force of well fluid through the subsurface pump is $W_{p L}$ [4]

$$
W_{p L}=\frac{1}{729} \frac{\rho_{L}}{\varepsilon_{\mu}{ }^{2}} \frac{A_{p}^{3}}{A_{o}^{2}}(S N)^{2}
$$

Where, $\varepsilon_{\mu}$ is the flow coefficient of valve; $A_{p}$ is the cross section area of piston; $A_{o}$ is the cross section area of valve hole ; $S$ is length of stroke ; $\mathrm{N}$ is pumping speed.

Considered, axial force at the bottom of a sucker rod during the up and down stroke $W_{x}$

$$
W_{x}=W_{f}+W_{b p}+W_{p L}
$$

Axial force on top of a segment of a sucker rod between two centralizers. Assuming that the rod string centralizer has been installed, calculating the axial force on top of a segment of a sucker rod between two centralizers. The axial force of the segment rod string included the segment rod string dead weight $W_{r d}$, inertial load $W_{a d}$, the buoyancy of the segment rod string $W_{f d}$ and the friction force between the segment rod string and liquid column $W_{r L}$.

(a) The segment rod string dead weight $W_{r d}$

$$
W_{r d}=\rho_{r} g A_{r} l
$$

Where, $\rho_{r}$ is the density of sucker rod; $l$ is assumed that the spacing between two centralizer, it is the length of segment sucker rod.

(b) The segment rod string inertia load $W_{a d}$

$$
W_{a d}=\frac{W_{r d}}{g} a_{d}
$$

Where, $a_{d}$ is acceleration of polished rod during down stroke.

(c) The buoyancy of the segment rod string $W_{f d}$

$$
W_{f d}=\rho_{L} g A_{r} l
$$

Where, $\rho_{L}$ is the density of liquid; $l$ is assumed that the spacing between two centralizer, it is the length of segment sucker rod.

(d) The friction force between the segment rod string and liquid column $W_{r L}$.

The maximum could be determined by the approximate formula below:

$$
W_{r L}=2 \pi \mu l\left[\frac{m^{2}-1}{\left(m^{2}+1\right) \ln m-\left(m^{2}-1\right)}\right] v_{\max }
$$

Where, $\mu$ is dynamic viscosity of the well fluid ; $\mathrm{m}$ is the ratio of the tubing and the diameter of sucker-rod, $m=\frac{d_{i t}}{d_{r}} ; d_{i t}$ is tubing; $d_{r}$ is the diameter of sucker-rod; $v_{\max }$ is the maximum descent velocity of sucker-rod.

From the above, the unit load of a segment of a sucker rod between two centralizers $q_{d}$ is :

$$
q_{d}=\left(W_{r d}-W_{a d}-W_{f d}-W_{r L}\right) / l
$$

Axial force on top of a segment of a sucker rod between two centralizers $W_{s}$ is :

$$
W_{s}=W_{x d}-q_{d} l=W_{x d}-\left(W_{r d}-W_{a d}-W_{f d}-W_{r L}\right)
$$


Where, $W_{x d}$ is axial force at the end of a segment of a sucker rod, at the first cross axial force at the end of a segment of a pump is $W_{x}$.

\section{Instability equation of a segment of a sucker rod between two centralizers}

Instability equation of a segment of a sucker rod between two centralizers is formula (11) which also is calculation of the placement distance between sucker rod centralizers. Solving the equation could obtain the spacing of interfacing sucker rod centralizer[5].

$$
l^{3}-\frac{2 W_{s}}{q_{d}} l^{2}-\frac{2 \pi^{2} E I}{q_{d}}=0
$$

Where, $E$ is material elastic modulus; $I$ is the cross-section moment of inertia of sucker rod.

\section{Calculation of two sucker rod centralizers spacing}

(1)When $W_{x d}=W_{x}$, using the root function in MATLAB software to solve formula (11), obtaining the first cross of sucker rod centralizer spacing $l_{1}$.

(2) Calculating the (i+1)st cross of sucker rod centralizer spacing axial force on top of a segment of a sucker rod $W_{s_{i+1}}, W_{s_{i+1}}=W_{s_{i}}-q_{d} l_{i}$ 。According to formula (11), using numerical method to get the (i+1) st crossing of sucker rod centralizer spacing $l_{i+1}$.

(3) When $W_{s_{i+1}} \leq 0$, arrival the neutral point of sucker rod, above the neutral point of sucker rod without centralizer.

\section{Application example}

A sucker-rod pumping pump depth is $1278 \mathrm{~m}$, submergence depth is $100 \mathrm{~m}$, plunger diameter is $32 \mathrm{~mm}$, length of stroke is $1.5 \mathrm{~m}$, pumping speed is $4 / \mathrm{min}$. Combination of sucker rod is . The density of well liquid is $0.85 \mathrm{t} / \mathrm{m} 3$, dynamic viscosity of the well fluid is $0.0324 \mathrm{pa} . \mathrm{s}$, dimension of inner diameter of tubing is $50.673 \mathrm{~mm}$, the number of traveling valve where in sucker rod piston is 2 . The clearance between piston and pump barrel radius is 2 , the flow coefficient of valve is 0.28 , the cross section area of piston is $0.0987 \mathrm{~m} 2$, the maximum descent acceleration of sucker-rod is $0.3142 \mathrm{~m} / \mathrm{s} 2$, the maximum descent velocity of sucker-rod is $0.24 \mathrm{~m} / \mathrm{s}$. Using the MATLAB software to optimize design of sucker rod centralizer spacing. Calculation results of centralizer spacing in table 1 ,Calculation results of centralizer location in table 2 .

Table 1 Calculation results of centralizer spacing

\begin{tabular}{ccccccccc}
\hline serial number & 1 & 2 & 3 & 4 & 5 & 6 & 7 & 8 \\
\hline $\mathrm{m}$ & 1.5 & 3.1 & 6.2 & 6.3 & 6.4 & 6.6 & 6.7 & 6.8 \\
\hline serial number & 9 & 10 & 11 & 12 & 13 & 14 & 15 & 16 \\
\hline $\mathrm{m}$ & 7 & 7.2 & 7.4 & 7.6 & 7.8 & 8.1 & 8.4 & 8.8 \\
\hline serial number & 17 & 18 & 19 & 20 & 21 & 22 & 23 & \\
\hline $\mathrm{m}$ & 9.3 & 9.9 & 10.6 & 11.6 & 13.2 & 16.3 & 30.8 & \\
\hline
\end{tabular}


Table 2 Calculation results of centralizer location

\begin{tabular}{ccccccccc}
\hline serial number & 1 & 2 & 3 & 4 & 5 & 6 & 7 & 8 \\
\hline $\mathrm{m}$ & 1276.5 & 1273.4 & 1267.2 & 1260.8 & 1254.4 & 1247.8 & 1241.1 & 1234.3 \\
\hline serial number & 9 & 10 & 11 & 12 & 13 & 14 & 15 & 16 \\
\hline $\mathrm{m}$ & 1227.3 & 1220.1 & 1212.7 & 1205.1 & 1197.3 & 1189.2 & 1180.7 & 1171.9 \\
\hline serial number & 17 & 18 & 19 & 20 & 21 & 22 & 23 & \\
\hline $\mathrm{m}$ & 1162.6 & 1152.8 & 1142.2 & 1130.5 & 1117.3 & 1101.1 & 1070.3 & \\
\hline
\end{tabular}

From the table 1 and table 2 we can figure out there are 23 centralizers. The spacing between the first and second centralizer is smaller, because the force of sucker rod which at the end of a segment of a pump is larger, centralizer arrangement closely; The 21st to 23rd centralizer spacing is larger, because the centralizer near the neutral point of sucker rod and the force of sucker rod is smaller, therefore centralizer arrangement sparse .The rest centralizer spacing from $6 \mathrm{~m}$ to $8 \mathrm{~m}$. Centralizer is usually installed in sucker rod collar in downhole, installing a centralizer interval for $8 \mathrm{~m}$, therefore, the result of optimum design of sucker rod centralizer spacing accords with the field operating requirements.

\section{Conclusions}

Optimum design of sucker rod centralizer spacing have considered bending deflection of sucker rod string during the up and down stroke, on the basis of instability equation of a segment of a sucker rod between two centralizers to calculate the optimum locating positions and intervals of sucker rod centralizers. The example analyzed shows that optimization design of sucker rod centralizer spacing is reasonable and feasible.

\section{Acknowledgements}

The authors would like to thank the Shaanxi Science and Technology Innovation Scheme (2015KTZDGY06-02), Key Problems of Industrial Science and technology of Shaanxi Province (2015GY110), (2016GY-185) and the Local Service Scheme of Shaanxi Province Education Department (15JF027) for financial support.

\section{References}

[1] C. Tan,X. Hu, D. Gao,Three-dimensional calculation of sucker rod centralizer spacing in deviated well, China Petroleum Machinery.25(1997)45-48.

[2] C. Yang, S. Fan,Y. Xu,et al,Side-abrasion of sucker rod string in straight hole , Journal of DaQing Petroleum Institute.24(20004) 68-70.

[3] Z. Huang, X. Luo,H. Wei,et al,Spacing configuration calculation method of sucker rod centralizer in three dimensional hole, Oil Drilling \& Production Technology.32(2010)60-63.

[4] B. Wan, Oil production equipment design and calculation, First edition,Petroleum Industry Press, Beijing, 1988 .

[5] N. Shi, J. Li,Design and computation for installing interval between centralizers of sucker-rod strings in vertical wells, Petroleum Drilling Techniques.35(2007)59-61. 